\title{
Asphalt layers within railway tracks' substructure
}

\author{
Al Qatamin Jehad ${ }^{1, *}$, Al Amir Ibrahim ${ }^{1}$ \\ ${ }^{1}$ Széchenyi István University, Department of Transport Infrastructure and Water \\ Resources Engineering \\ Egyetem tér 1., 9026 Győr, Hungary \\ *e-mail: Qataminjihad@yahoo.com
}

Submitted: 02/06/2021; Accepted: 04/11/2021; Published online: 24/11/2021

Abstract: For both heavy cargo Rail lines and High-Speed Lines, the railway industry continues to develop railway track design technologies. Within the past years, using an asphalt layer as a part of the railway track became so common as a support layer, it helps to reduce noise and vibration levels, reduce the thickness of the cross-sectional layers, reduce the lifetime maintenance, and many other great advantages. This paper will discuss the application of asphalt layers in railways, functionality, application fields, and types of asphalted trackbeds. Design requirements and parameters of asphalt layers, the mix design, installation process, and international experiences will be mentioned. Asphalt layers can improve the overall performance of the trackbeds and their behavior under repeated stresses of trains, the effect of asphalt layers on stress and strain ratios will be briefly discussed.

Keywords: asphalt underlayment, asphalt mix design, stress and strain ratios, asphalt trackbeds performance.

\section{Introduction}

Ancient Railway track designs simply consisted of two parallel rails fixed on wooden sleepers or ties, as in figure 1, those sleepers were just put on the natural ground. by the time people recognized that they should improve the performance of that kind of trackbed so they thought that it could be more efficient if they underlay and surround the cross ties or sleepers with a natural stone aggregate (ballast), they noticed that this stone aggregate layer restrained the horizontal and vertical 
movement and reduced the displacement as well. And that was the first ballasted track beds.

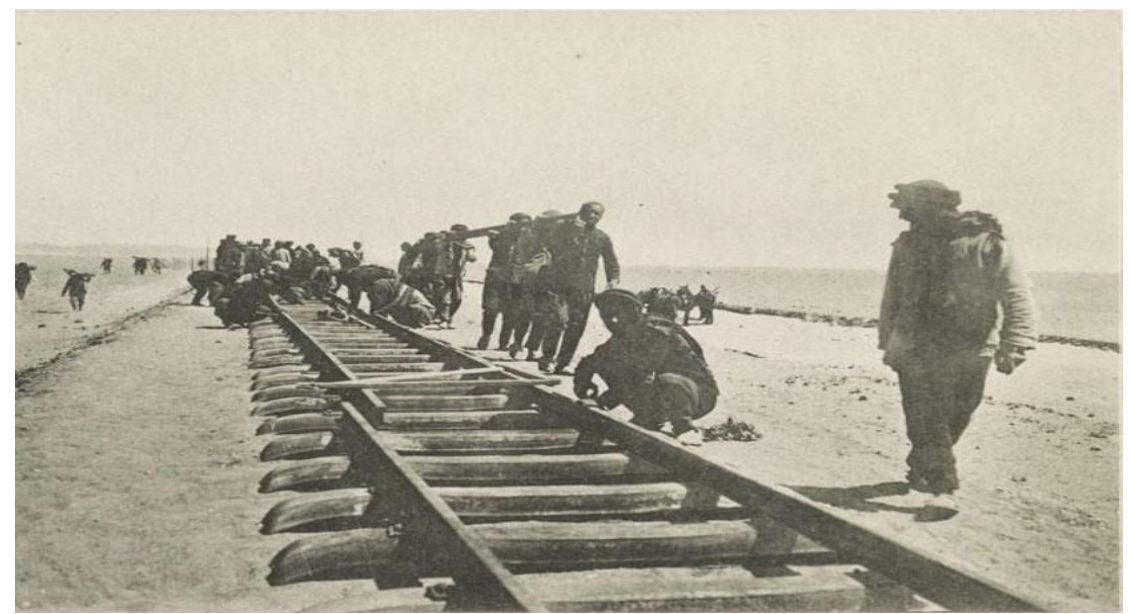

Figure 1. The old Railway of Alhijaz 1902 [11]

With the evolution and the development of trains and the need for heavier loads and more speeds, also the need for higher numbers of trains, railways had to be more efficient with larger rail profiles and more ties, to provide good load distribution and to reduce the effect of these loads on the subgrade materials, a sub-ballast granular layer was provided with a specific thickness.

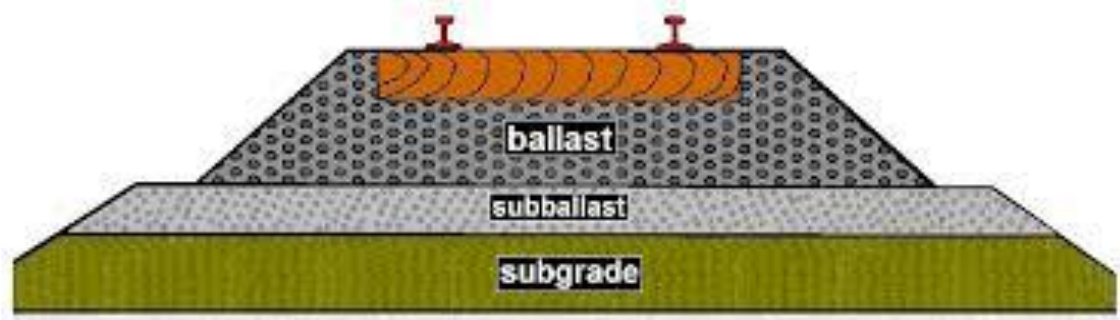

bedrock

Figure 2. Typical all-granular trackbeds cross-section. [1]. 
This layer has a smaller maximum aggregate diameter than the ballast, and it has a well-graded granular composition. This layer acted as a waterproof layer due to its low void ratio and low permeability [1]; so, it drives the water away from the track. As a result, better trackbeds with mainly all granular layers have better performance and more bearing capacity. This type of trackbed requires a drainage system to prevent water from seeping down into the sub-ballast and the subgrade to avoid the undesirable effect of water on those layers. Figure 2 shows the typical allgranular trackbeds cross-section.

Later on, the trackbeds need to be more stable and more load distribution efficient, and hence it reduces subgrade stresses and prevents softening and deformation of the subgrade layers. So, the asphalt underlayment-as showed in figure 3- appeared to be the perfect solution. This asphalt layer is quite similar in Mix Design to the one used in highway construction. [2].

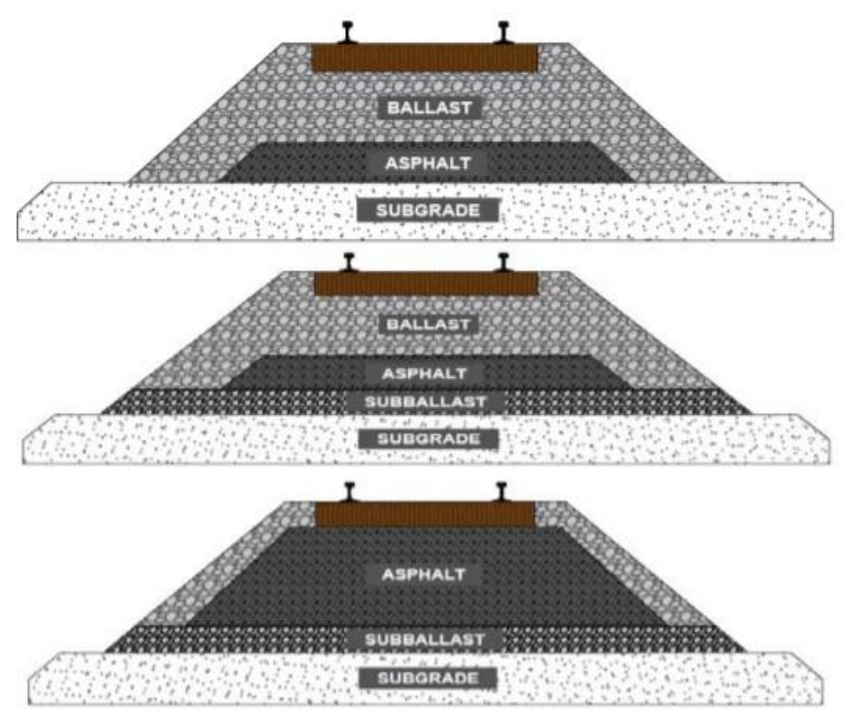

Figure 3. Asphalt underlayment [3]

\section{Asphalt}

Asphalt is mainly a mixture of aggregate and bitumen. See figure 4. Bitumen is the resulting material of the distillation of crude oil. Aggregate in asphalt should be well-graded and combines particle sizes from fine to coarse aggregate, the properties of asphalt mixture can differ in accordance to the construction 
requirements; these properties can be controlled by varying the proportions of the mixture's compositions, it could be rigid and stable or flexible.

Some projects require exact specifications for the asphalt; such as heavy-duty and lower temperatures; this could be done by adding some special additives or using polymer modified bitumen.
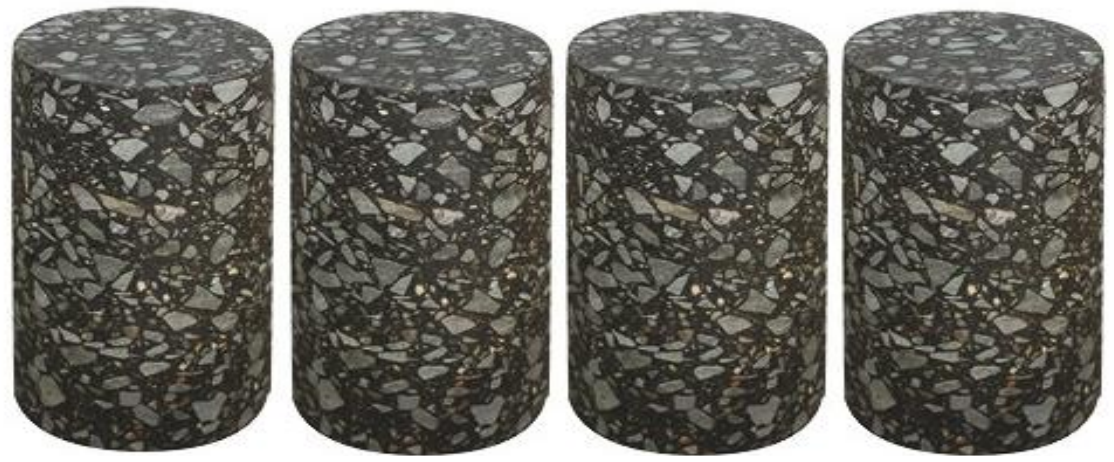

Figure 4. Core samples show the composition materials of asphalt.[12]

Asphalt pavement should meet the basic requirements in terms of use:

1- Strength: asphalt pavement should be strong enough to resist the stresses coming from the loads above to avoid cracking and failure.

2- Durability: durability could be affected by many factors such as temperature, humidity, excess loads, and the performance of each component.

3- Stability: stability is the term that describes the consistency of performance level due to the change of the affecting factors, such as temperature and the existence of water.

\section{The functionality of Asphalt in railways}

Because of the accelerated growth in traffic volumes, train numbers, and heavy loadings, it was necessary to customize the railways and provide better characteristics of railways that make them more supportive, stronger, and longerlasting. Because of its good properties, hot mixed asphalt has to provide trackbeds with the desired features that are needed in railway structures. Asphalt to be added as a layer to be a medium-modulus, flexible, low-voids, fatigue-resistant layer that can withstand heavy tensile strains without cracking. [10]. The addition of an asphalt layer to the trackbeds -see figure 5- can increase the bearing capacity and protect the 
substructure layers beneath besides its perfect separation function, [9] it also can do a great job in terms of separation; it prevents the fine-graded materials from the subballast or subgrade to seep up to the ballast. The asphalt layer to be used as a supplementary layer within the railway trackbed could play a major role as a load distributor layer which will consequently reduce the settlement while the trackbed is on loading [14]. Thanks to the asphalt waterproofing ability to replace the use of additional geomembrane. The functionality of asphalt in railways could be counted as follows:

1- A strong-supportive layer below the ballast distributes the loads uniformly to the substructures.

2- A waterproofing layer prevents the water seepage and keeps the necessary consistency of load-bearing capacity in the trackbed structure.

3- Ease the water's movement toward the side ditches as it is an impermeable layer with a low void ratio.

4- Prevent the fine-graded materials from pumping up and mix with the Ballast.

5- A Resilient layer tends to reduce noise and vibration.

6- Longer-lasting trackbeds and lower maintenance costs.
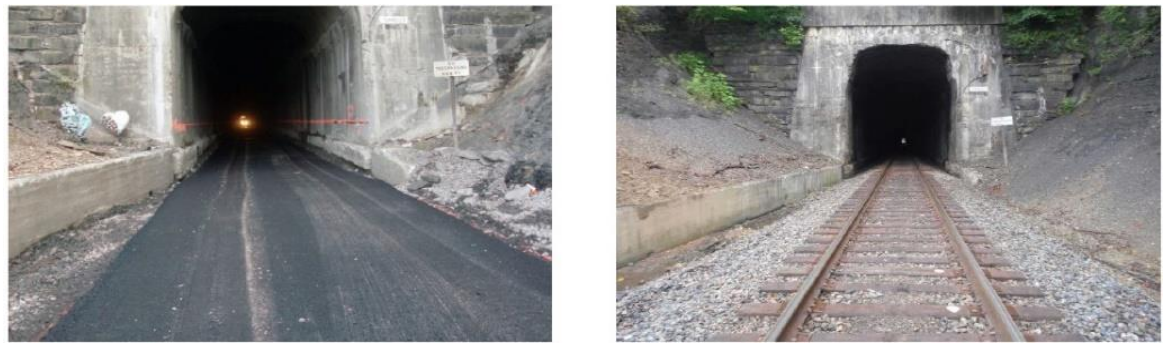

Figure 5. Asphalt layer under ballast [3]

\section{Asphalt applications in railways}

The properties of asphalt offer an ideal solution for many problems and applications in railways construction; it improves both the stability and durability of the track beds and consequently reduces the maintenance needs; it could also be a perfect solution when a lesser construction height of superstructure is a must especially in tunnels and bridges. 


\subsection{Types of asphalt trackbeds}

Asphalt could be involved in the construction design of tracked within two basic patterns; either hot mix asphalt as a sub-ballast layer or hot mix asphalt overlayment layer designs could be adopted in trackbeds.

Asphalt as a sub-ballast layer could also be divided into two designs; the socalled "asphalt underlayment" and "asphalt combination" trackbeds, both of them consider the ballast layer as a part of the structural design. [1]. The ballast layer will play a crucial role as it offers a cover to protect the asphalt from the sunlight, air, and water, and it also keeps a stable environment and temperature above the asphalt, which leads to a longer asphalt lifetime. [4].

\subsubsection{Asphalt underlayment}

This type of trackbed has almost the same cross-section as the all-granular cross-section but the substitution of the sub-ballast layer with the asphalt layer. So, the asphalt layer is placed directly on the subgrade. The typical cross-section is shown in figure 6 .

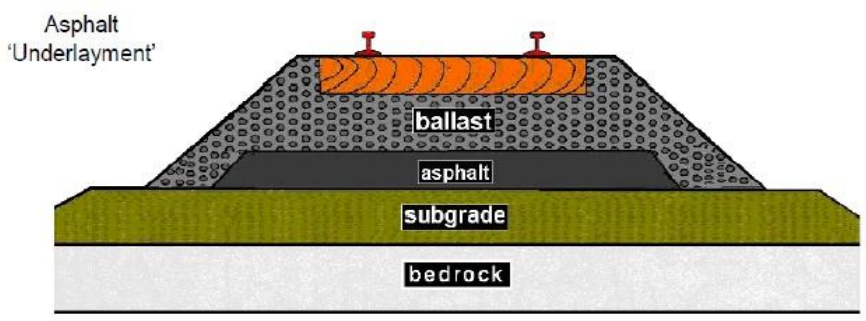

Figure 6. Asphalt underlayment trackbed cross-section without sub-ballast layer. [1]

\subsubsection{Asphalt combination}

The asphalt layer is an additional layer placed between the ballast, and the subballast layer, the thickness of the asphalt layer is lesser than the one used in asphalt underlayment trackbeds; this is because of the existence of the granular sub-ballast layer below. Figure 7 shows this design. 


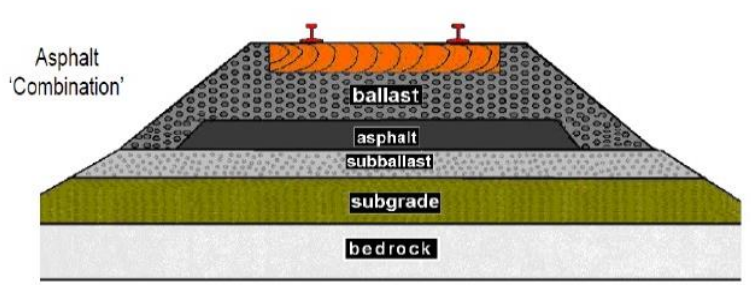

Figure 7. Asphalt combination trackbed cross-section with sub-ballast layer. [1]

\subsubsection{Ballast-less trackbeds}

This type of trackbed has the sleepers placed directly on the asphalt layer. So, there is no ballast layer placed on the top of the structure. The asphalt layer and the granular sub-ballast layer should be relatively thick to compensate for the deleted ballast layer, cribbing rock should be used to restrain sleepers from both lateral and longitudinal movement. as showed in figure 8 .

Normal paving machines are being used for such trackbeds, and it is possible to reach a level of accuracy up to \pm 2 millimeters, resulting in a perfect level and stiff surface for the sleepers to be fixed over it, trackbed and sleepers are filled with elastic synthetic material or a granular ballast could be used between sleepers as an extra stability option. [2].

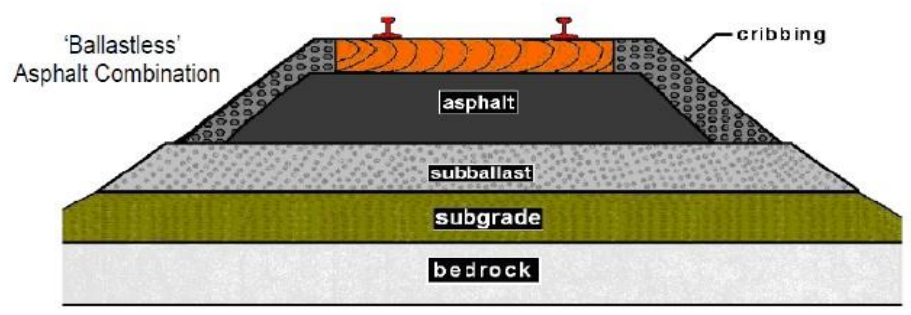

Figure 8. Asphalt ballast-less trackbeds cross-section. [1]

A horizontal anchoring system should be used for the rail track while constructing the ballast-less trackbed design; to prevent the transverse movement of rails. This kind of design allows for lowering the base of the trackbed as it eliminates the ballast layer so, this is an option to consider for tunnels.

The most important feature of this design is elasticity, particularly; when polymer-modified asphalt is being used. Also, it is considered a time-saving system because the construction could take place immediately after the asphalt cools down, 
maintenance and small corrections could be done without demolishing and reconstruction. In the 1990s, the first successful ballastless track was built in Germany. Since then, this design has started to appear in many other countries. [5]

\subsection{Application fields}

Hot mix asphalt underlayment tended to be used where there is heavy rail traffic, and one or more of the following conditions exist.

1- When a strong, and durable substructure below ballast is difficult to be set up and maintained.

2- When a good drainage surface for water is difficult to be set up and maintained.

3- When lowering the groundwater table to prevent the weakening of the trackbed is difficult.

4- When stresses are expected to be relatively high. Such as joints and approaches of bridges and tunnels.

Moreover, Hot-Mix-Asphalt could be used for the maintenance and rehabilitation of the tracks as it provides in some cases a cheaper solution to maintain an acceptable operating performance in locations that have a high conventional maintenance cost. Railway ballast is a non-cohesive, granular crushed rock that has a poor capacity to bear vibrations caused by trains [17]. So, the existence of asphalt underlayment can improve the vibration absorption and will reduce the maintenance needs.

In some specific track works, such as crossings and turnouts, the trackbed tends to break down faster. So; more maintenance cycles are needed; The existence of the hot-mix-asphalt layer has proven that it improves performance and reduces maintenance costs in those areas. [6].

\section{Asphalt trackbed parameters}

In the early 1980s, asphalt trackbed design properties have developed and changed following the design requirements.

\subsection{Asphalt layer thickness and width}

The width of the asphalt layer for underlayment trackbeds designs is around $3.6-3.7 \mathrm{~m}$; As in figure 9. This width provides $0.5 \mathrm{~m}$ as an asphalted space beyond the sleepers. [1].

Some special trackwork requires a wider asphalt layer, some crossings are provided with 7.5 - $30 \mathrm{~m}$ asphalt width beyond the sleepers. Asphalt underlayment 
thickness depends on the quality of subgrade support, traffic loading, and type of installation. [1].

In average support conditions, a layer of 125 to $150 \mathrm{~mm}$ thickness is adequate, but for the poor support conditions and high impact areas, a minimum 200-300 mm asphalt layer thickness is required. [1].

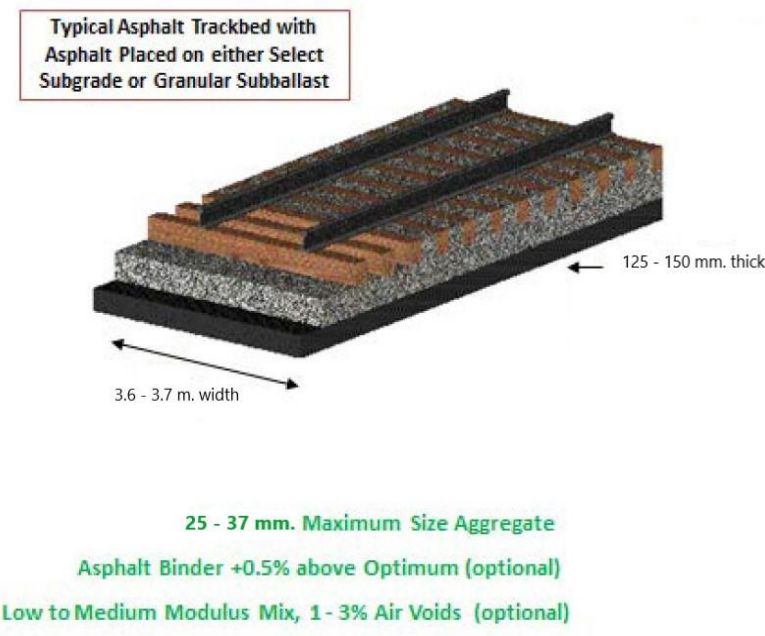

Figure 9. Typical asphalt trackbed parameter [3]

\subsection{Asphalt mixture}

When the asphalt is designed to be a part of the structural system of the trackbed, it is recommended that the mix should be a low modulus (plastic) mix, with a design air-void percentage of $1-3 \%$, and in place air-void percentage of less than 5\%. Furthermore, the maximum aggregate size is almost the same as the highway pavement mix; 25 to $37 \mathrm{~mm}$ is perfect for such a pavement. (Table 1 shows a suggested aggregate gradation for both underlayment and overlayment).

Binder content should be increased by $0.5 \%$ above the optimum binder content used for highway pavements to make the mix easier to be compacted. The binder used for trackbeds should be AC-10 or AC-20 viscosity-grade. The viscosity of 
asphalt is usually measured at $60{ }^{\circ} \mathrm{C}$. This bitumen grade is usually used for road construction and asphalt mixtures with superior properties.

Table 1. A suggested aggregate gradation suitable for both underlayment and overlayment [7]

\begin{tabular}{|c|c|}
\hline Sieve size & Percent passing \\
\hline $1-1 / 2$ in. $(37.5 \mathrm{~mm})$ & 100 \\
\hline $1-$ in. $(25.0 \mathrm{~mm})$ & $90-100$ \\
\hline $3 / 4$ in. $(19.0 \mathrm{~mm})$ & --- \\
\hline $1 / 2$ in. $(12.5 \mathrm{~mm})$ & $70-90$ \\
\hline $3 / 8$ in. $(9.5 \mathrm{~mm})$ & --- \\
\hline No. 4 & $40-65$ \\
\hline No. 10 & $25-45$ \\
\hline No. 40 & $10-26$ \\
\hline No. 80 & $6-18$ \\
\hline No. 200 & $3-8$ \\
\hline $\begin{array}{c}\text { Percent AC-10, } 20 \text { OR } 30 * \text { Asphalt } \\
\text { Cement }\end{array}$ & $4-8$ \\
\hline *Based upon total weight of \\
mixture
\end{tabular}

\section{Asphalt installation}

Installation equipment needed for the new construction of trackbeds is almost the same as the equipment needed for highway construction. Asphalt is placed with conventional paving machines and compacted with vibratory rollers.

For an old trackbeds rehabilitation, the track should be removed first, and then excavations take place to the perfect depth as per the specification of the design, asphalt mix to be placed and paved as normal highway paving procedure. See figure 10. To provide positive drainage for the water away from the trackbed; the top of the hot mix asphalt should slightly be crowned or sided sloped at the same time, it should be leveled with the shoulders or a little higher. A proper drainage system necessitates a well-formed substructure crown, appropriate water spillage material, and relatively clean ballast. A protective layer that can guarantee drainage and bearing capability is required for a longer lifetime. [13]. 
If the asphalt layer is only $150 \mathrm{~mm}$ thick, it could be placed all at once as one lift, and if the asphalt layer has a higher thickness than $150 \mathrm{~mm}$, it should be placed as lifts of $100 \mathrm{~mm}$ thick for each. The asphalt mix is best compacted when the temperature of the mixture is between 100 and $150{ }^{\circ} \mathrm{C}$, and this is to achieve the perfect air voids ratio and the desired compaction degree; which is $95 \%$ of the maximum density or higher. [6].

Even though the construction of the asphalt protection layer is costly, the lifetime cost is more economical than alternative protection layers in the long run. This is due to the slower aging that the asphalt layer provides which leads to lower cost maintenance [15].

\section{Stress and strain ratios in highways and railways}

Depending on the base type, either full-depth asphalt, underlayment, or overlayment, for both highways and asphalted railways, and the thickness of hot mix asphalt layer, stress, and strain ratios will vary in different ways. The effect of hot mix asphalt and its thickness is showed in figure 11. [8].
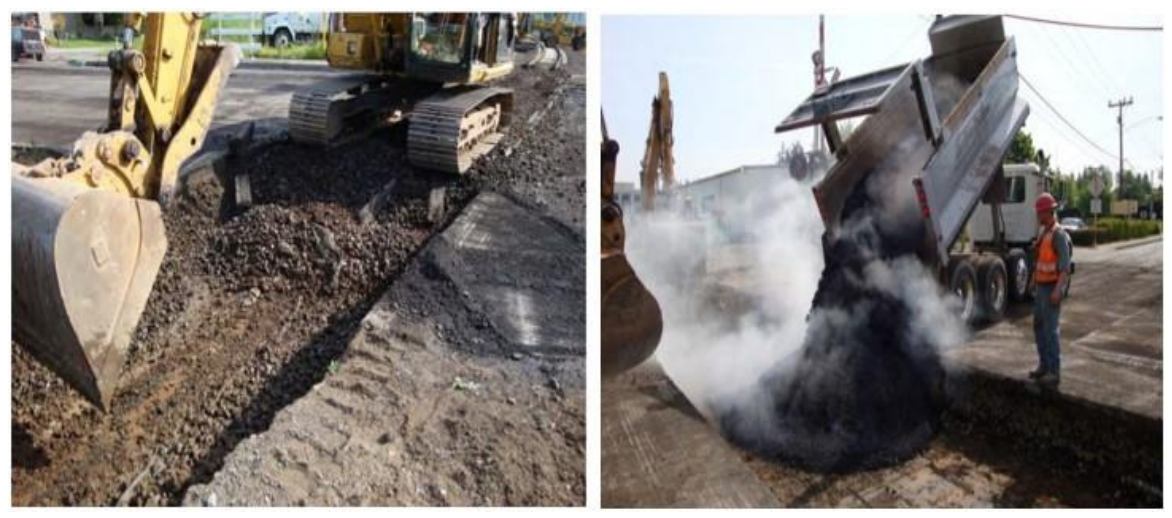

Figure 10. Rail/highway crossing rehabilitation. [1]. 

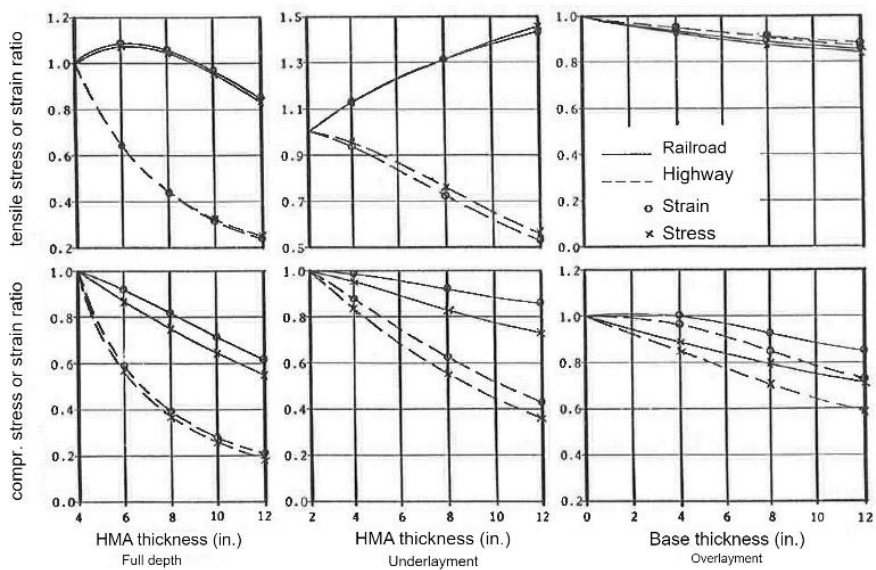

Figure 11. Effects of thickness on stress and strain ratios. [8].

The contact pressure for highways is the tire contact pressure, which is different in the railways where the maximum contact pressure is between sleepers and the underneath layers. From figure 11, many points could be summarized to explain the effect of the hot mix asphalt layer on the stress and strain for both compressive and tensile states. [8].

1- In full-depth asphalt, tensile strain, and tensile stress, both are affected in the same way by increasing the asphalt layer's thickness as the curves of stress and strain are close to each other.

2- Increasing the thickness of hot mix Asphalt in highways will decrease the tensile strain, but for railways, it is not necessary. Increasing hot mix asphalt underlayment thickness will increase the tensile strength for the railroad, this is because of the concentration of loads near the wheels due to the increasing contact pressure. (Contact pressure increases by the increase of hot mix asphalt thickness).

3- To reduce the strain in the railroad trackbed; it is more effective to use a thicker base course rather than using a thicker asphalt layer.

4- The thickness of hot mix asphalt has a different effect on compressive strength and compressive stress, as there is a large space between the curves of stress and strain. So, it is preferable to use compressive stress for the design as it is more sensitive to thickness changes. 
5- The effect of thickness on compressive stress in highways is much greater than its effect on railway trackbed, and this is due to the load distribution difference; in highway, the tire loads are distributed on a small area, but in railways trackbed, the loads are distributed through rails and sleepers on a large area.

By using hot mix asphalt underlayment design in railways, the thickness of asphalt has a significant effect on compressive strength as the increased thickness will decrease the compressive stress.

\section{Performance of asphalted trackbeds}

The asphalted trackbed was being under monitoring to record the overall performance and the operating system evaluation.

\section{Trackbed moisture}

That existence hot mix asphalt will maintain the moisture level in the layers beneath the asphalt at or very close to the optimum moisture content; due to the Asphalt waterproofing role, which consequently leads to provide a consistent loadcarrying capability for the layers below, also preventing pumping of subgrade materials to the ballast.

\section{Long term settlement}

The use of asphalt in railways improves track performance in terms of longterm settlement even in the existence of low stiffness subgrade, and this is because of its high stiffness related to the weak subgrade stiffness and the ability of asphalt to redistribute the loads.

\section{Track geometry}

The geometric parameters; (alignment, gage, and elevation) were periodically monitored in railways, asphalted track lines were being geometrically tested at six months intervals; those tests didn't show any changes in geometric parameters.

The tested track lines were historically in need of high maintenance costs before rehabilitation, due to weak support and drainage problems.

\section{Long-term operating costs}

By keeping the trackbed quality insured, the operating costs will be reduced, as the operating efficiency of the train movement is improved. Maintaining a proper track geometry will increase the speed and safety of operating systems of trains, it also reduces train resistance and fuel consumption. Less resistance means lesser wear and repair for rolling stocks. 


\section{Failure modes in asphalt}

Asphalt roadway pavements are prone to the following breakdown modes:

1) High-temperature rutting.

2) Low-temperature cracking and fatigue.

3) Stripping/raveling on wet surfaces due to the suction of high wheel pressures.

4) Progressive fatigue cracking owing to insufficient subgrade support, which is often exacerbated by excessive moisture and poor drainage.

These circumstances do not exist on railway trackbeds made of asphalt. Temperatures, for instance, aren't high enough to encourage rutting. In the insulated trackbed environment, however, the temperatures are not low enough to cause low temperature cracking and lower fatigue life, and neither does the asphalt binder weather or harden excessively, which would have a detrimental impact on cracking and fatigue life. Because there is no rubber suction action in the trackbed environment, the potential to strip/ravel is largely avoided. [16].

\section{International applications and experiences}

Many countries adopted the asphalt track bit systems as a response to the high demand for stronger and durable rail lines.

\subsection{Asphalt railways applications in Italy}

From the early 1970s, asphalt mixes have been used in Railway Construction in Italy; more than $1200 \mathrm{~km}$ of asphalted trackbeds are used now. The experience showed great results in terms of high-stress elimination, protecting the embankments, eliminate Ballast fouling, and distributing the static and dynamic loads. The Italian asphalted Railway systems adopt the asphalt underlayment systems; where the cross-section consists of a super-compacted sublayer over the embankment, asphalt sub-ballast, ballast, sleepers, and rails. as shown in figure 12 .

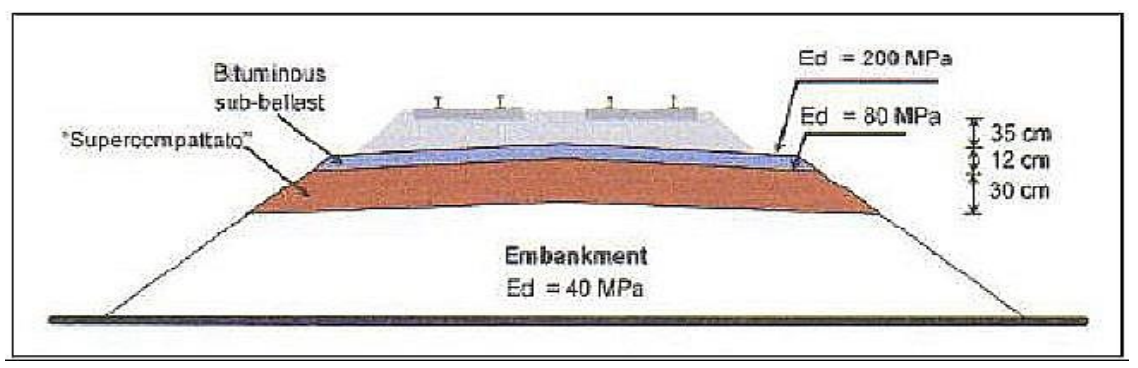


Figure 12. Italian high-speed railways cross-sectional profile. [1].

The bearing capacity of the embankment must be $40 \mathrm{MPa}$ over it there, will be a super compacted layer with a bearing capacity of $80 \mathrm{Mpa}$, and a minimum thickness of $30 \mathrm{~cm}$, consists of a sand /gravel mixture crowned with a slope of $3.5 \%$.

The asphalt mixture for the sub-ballast has a maximum aggregate size of $25 \mathrm{~mm}$. The thickness of the layer is $120 \mathrm{~mm}$, and it covers the whole track cross-section. The asphalt layer must have a minimum of $200 \mathrm{Mpa}$; To be able to carry the repeated loads which come from the movement of the trains. The Italian experience showed that the asphalt layer is very effective in improving the overall performance of trackbeds. [1]. The following advantages were proven:

- Reduced vibrations and Noises.

- A reduced overall thickness of the trackbed.

- Lesser maintenance costs.

- Better water drainage protects the trackbed.

\subsection{Asphalt railways applications in France}

In France, the traditional railways' cross-section consists of a ballast layer of 300 $\mathrm{mm}$ thickness sets on a $200 \mathrm{~mm}$ thick sub-ballast layer, while a $500 \mathrm{~mm}$ thick layer of limestone carries the upper layers. In 2005 the French national railways brought the new concept of asphalted railways, where the $500 \mathrm{~mm}$ thick layer is replaced by two layers; the upper one is an asphalt layer with $140 \mathrm{~mm}$ thickness, and the lower one is called the adjustment layer with $200 \mathrm{~mm}$ thickness, which means that the thickness is reduced by $140 \mathrm{~mm}$. To protect the adjustment layer against the construction equipment; a surface addressing is applied, another surface dressing is applied over the asphalt layer too. [5]. figure 13 shows the cross-sectional profile for each traditional and asphalted railway in France.

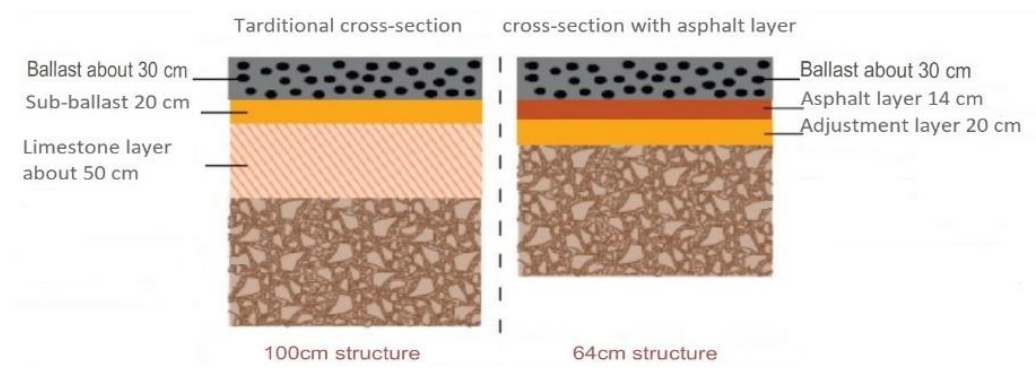

Figure 13. Traditional and asphalted sub-ballast cross-sections in France [5] 


\subsection{Asphalt railways applications in Japan}

For several years, asphalted lines in Japan have been commonly used on highSpeed and normal railway lines in railway ballast tracks. The first goal was to support the ballast effectively and to eliminate track irregularities using asphalt track beds, the load level in the subgrade is also decreased to stop subgrade deformations. [5] The performance-based design process has three separate standard performance designs:

- Rank I performance: ballastless roadbed or asphalt roadbed.

- Rank II performance: Asphalt roadbed for the ballasted track.

- Rank III Performance: Crushed stone roadbed for the ballasted track which is the typical design using granular layers only.

The Performance Rank I is a ballast-less slab track with a concrete or asphalt supporting where sleepers are directly fastened to the slab. It is designed as the highest quality track in Japan. It is designed and tested for track settlement, concrete reinforcement base breakage, fatigue, cracking, and thermal stresses. For the Performance Rank I asphalt ballast-less track, the typical dimensions are:

- Slab width: $2220 \mathrm{~mm}$

- Concrete slab thickness: $190 \mathrm{~mm}$

- Asphalt-concrete base thickness: $150 \mathrm{~mm}$

- Well graded crushed stone layer thickness: $150 \mathrm{~mm}$

A ballasted track with a $50 \mathrm{~mm}$ thick asphalt layer is the Performance Rank II design. As shown in figure (14). Because of the ability of asphalt to spread loads and promote drainage, this style has been used for over 30 years in Japan. The design requirements for the performance rank II design are track settlement and fatigue damage to the asphalt. the typical dimensions are:

- Ballast thickness under the sleeper: 250-300 mm.

- Asphalt layer thickness: $50 \mathrm{~mm}$.

- Well-graded crushed stone layer thickness: 150-600 mm. 


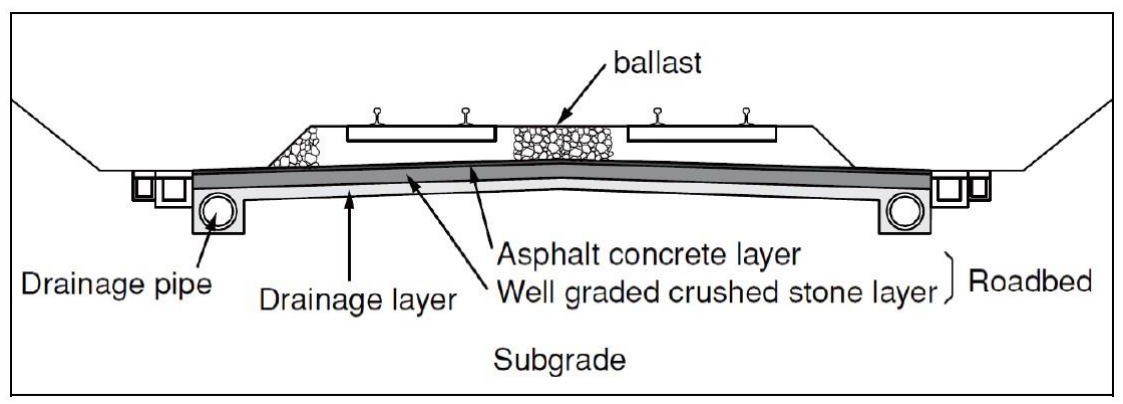

Figure 14. Performance Rank II design [5]

\subsection{Asphalt railways applications in Germany}

In Germany, Deutsche Bundesbahn AG (DB AG) concluded that the rail web (rails and sleepers) with a ballast bedding type of construction had reached a level that could hardly be improved as a classical construction method for railroad tracks.

Asphalt will replace the load-bearing ballast. For the first time in Germany, this construction method was used about 35 years ago, with a base level in asphalt. Since then, DB AG has accepted several systems of the asphalt design concept. They are the following, in detail [5]:

- ATD Asphalt base course with a rail web

- SATO Concrete sleeper or Y-steel sleeper with double base

- Walter System Walterbau

- Getrac German Track Corporation Asphalt.

\section{Conclusion}

The asphalt layer is being used worldwide now in combination with granular layers to add the preferable properties of asphalt to the trackbed; the main purpose of asphalt in railways is to provide an additional supportive, waterproofing layer to bear the repeated stresses coming from the movement of trains, also to be a load distributor layers to increase the lifetime of the tracked.

When asphalt underlayment is used with a conventional ballasted track, the track stiffness increases, and total settlement decreases. This is directly impacting the cost of track maintenance. Furthermore, as compared to a typical granular sub-ballast, ballasted rails with asphalt layers will require less maintenance.

The amount of stress and strain beneath an asphalt layer in a railway track is mostly determined by the thickness of the layer; however, substituting granular 
materials with asphalt pavement can reduce the total height of the ballasted railway track. This is a critical consideration in situations where the total height of the trackbed must be critically controlled, such as tunnels and bridges.

When it comes to ballastless railway tracks, asphalt is an excellent choice. It offers a good degree of stiffness balance throughout the track system, which is critical for overall stability and, at the same time, response to the train's dynamic loads.

Many countries adopted this technology and tested it during the last years it was clear that the presence of asphalt either as an underlayment or instead of ballast carried the railway industry to a new level.

Using asphalt in railway trackbed increases maintenance cycles' gaps. However, using new asphalt technologies such as self-healing asphalt and nanoparticles in asphalt will promote the performance of the railway trackbed in general and transfer it to a new level.

More studies are being made to reach the best combination and form of using the asphalted trackbeds.

\section{Acknowledgment}

The publishing of this paper was supported by Professor Szabolcs Fischer.

\section{References}

[1] Jerry G. Rose, Reginald R. Souleyrette, Asphalt Railway Trackbeds: Recent Designs, Applications, and Performances, AREMA 2015.

[2] Coenraad Esveld. Modern Railway Track. Second ed., Zaltbommel, Mrt Productions, 2001.

[3] Jerry G. Rose, Asphalt Underlayment Railway Trackbeds: Designs, Applications, and Long-Term Performance Evaluations, NURail Project ID: NURail 2017-UKY-R12b, 2017.

[4] Jerry G. Rose, Henry M. Lees, Jr., Long-Term Assessment of Asphalt Trackbed Component Materials' Properties and Performance, 2008.

[5] European Asphalt Pavement Association (EAPA), Asphalt in Railway Tracks, EAPA Position paper, June 2014.

[6] Jerry G. Rose, E. Ray Brown, and Monica L. Osborne, Asphalt Trackbed Technology Development the First 20 Years, Transportation Research Record 1713, Paper No. 00-0207, 2000. 
[7] Jerry G. Rose and M. J. Hensley, Performance of hot-mix-asphalt railway trackbeds, Transportation research record 1300, 1991.

[8] Yang H. Huang, Jerry G. Rose, and Charles J. Khoury, Hot-mix asphalt railroad trackbeds, Transportation research record 1095, 1986.

[9] B. Eller, Sz. Fischer, Tutorial on the emergence of local substructure failures in the railway track structure and their renewal with existing and new methodologies, Acta Technica Jaurinensis, Vol. 14, No. 1, pp. 80-103, 2021.

[10] Jerry G. Rose, Lindsey Sebastian Bryson, Hot Mix Asphalt Railway Trackbeds: Trackbed Materials, Performance Evaluations, and Significant Implications, The International Conference on Perpetual Pavements, 2009.

[11] Moritz, B. (1916) Bau der Hiğâzbahn Schienenlegung bei Tebûk. Saudi Arabia, 1916. Berlin: Dietrich Riemer. [Photograph] Retrieved from the Library of Congress, https://www. loc.gov/item/96513602/

[12] Gilmore \& Associates, Inc, Infrastructure management plan, Narrative report, prepared for Borough of Conshohocken, 2018.

[13] Eller, B. and Fischer, S., 2019. Review of the modern ballasted railway tracks' substructure and further investigations. Science and Transport Progress. Bulletin of Dnipropetrovsk National University of Railway Transport, 0(6(84), pp.72-85.

[14] Fischer, S., 2021. Investigation of effect of water content on railway granular supplementary layers. Naukovyi Visnyk Natsionalnoho Hirnychoho Universytetu, (3), pp.64-68.

[15] Fischer, Szabolcs \& Eller, Balázs \& Kada, Zoltán \& Németh, Attila. (2015). Railway construction. Györ: Universitas-Györ Nonprofit Kft., pp.54-55.

[16] Sehgal, V., Sehgal, L., Garg, A. and Buttlar, W., 2017. Hot Mix Asphalt in Ballasted Railway Track: International Experience and Inferences. [online] Iricen.gov.in. Available at: <https://www.iricen.gov.in/iricen/ipwe_seminar/2017/36.pdf> [Accessed 4 October 2021].

[17] Sysyn, M., Nabochenko, O., Kovalchuk, V., Przybyłowicz, M. and Fischer, S., 2021. Investigation of interlocking effect of crushed stone ballast during dynamic loading. Reports in Mechanical Engineering, 2(1), pp.65-76. 